NBER WORKING PAPER SERIES

\title{
THE IT REVOLUTION AND THE GLOBALIZATION OF R\&D
}

\author{
Lee G. Branstetter \\ Britta M. Glennon \\ J. Bradford Jensen \\ Working Paper 24707 \\ http://www.nber.org/papers/w24707 \\ NATIONAL BUREAU OF ECONOMIC RESEARCH \\ 1050 Massachusetts Avenue \\ Cambridge, MA 02138 \\ June 2018
}

We gratefully acknowledge financial support from the National Science Foundation through two grants: 1360165 and 1360170. The statistical analysis of firm-level data on U.S. multinational companies was conducted at the Bureau of Economic Analysis (BEA), United States Department of Commerce under arrangements that maintain legal confidentiality requirements. The views expressed do not reflect official positions of the U.S. Department of Commerce or NSF. We thank Bill Zeile, Jim Fetzer, and Ray Mataloni for helpful discussions on the BEA data. We thank Josh Lerner, Scott Stern, and Kyle Meyers for valuable comments All errors and omissions remain our own responsibility. The views expressed herein are those of the authors and do not necessarily reflect the views of the National Bureau of Economic Research.

At least one co-author has disclosed a financial relationship of potential relevance for this research. Further information is available online at http://www.nber.org/papers/w24707.ack

NBER working papers are circulated for discussion and comment purposes. They have not been peer-reviewed or been subject to the review by the NBER Board of Directors that accompanies official NBER publications.

(C) 2018 by Lee G. Branstetter, Britta M. Glennon, and J. Bradford Jensen. All rights reserved. Short sections of text, not to exceed two paragraphs, may be quoted without explicit permission provided that full credit, including $(\odot$ notice, is given to the source. 
The IT Revolution and the Globalization of R\&D

Lee G. Branstetter, Britta M. Glennon, and J. Bradford Jensen

NBER Working Paper No. 24707

June 2018

JEL No. F23,O32,O57

\begin{abstract}
$\underline{\text { ABSTRACT }}$
Since the 1990s, R\&D has become less geographically concentrated, and has seen especially fast growth in emerging markets. One of the distinguishing features of the R\&D globalization phenomenon is its concentration within the software/IT domain; the increase in foreign R\&D has been largely concentrated within software and IT-intensive multinationals, and new R\&D destinations are also more software and IT-intensive multinationals than traditional R\&D destinations. In this paper we document three important phenomena: (1) the globalization of $R \& D$, (2) the growing importance of software and IT to firm innovation, and (3) the rise of new R\&D hubs. We argue that the shortage in software/IT-related human capital resulting from the large IT- and software-biased shift in innovation drove US MNCs abroad, and particularly drove them abroad to "new hubs" with large quantities of STEM workers who possessed IT and software skills. Our findings support the view that the globalization of US multinational R\&D has reinforced the technological leadership of US-based firms in the information technology domain and that multinationals' ability to access a global talent base could support a high rate of innovation even in the presence of the rising (human) resource cost of frontier R\&D.
\end{abstract}

Lee G. Branstetter

Heinz College

School of Public Policy and Management

Department of Social and Decision Sciences

Carnegie Mellon University

Pittsburgh, PA 15213

and the Peterson Institute for

International Economics

and also NBER

branstet@andrew.cmu.edu

Britta M. Glennon

Heinz College

School of Public Policy and Management

Carnegie Mellon University

Pittsburgh, PA 15213

bglennon@cmu.edu
J. Bradford Jensen

McDonough School of Business

Georgetown University

Washington, DC 20057

and Peterson Institute for

International Economics

and also NBER

jbj24@georgetown.edu 


\section{Introduction}

The distribution of US multinational R\&D investment across countries and industries has undergone a dramatic shift since the 1990s. Foreign R\&D has grown dramatically; between 1989 and 2013, US multinational foreign R\&D expenditure grew seven-fold (Bureau of Economic Analysis). Furthermore, the location of foreign R\&D has shifted; traditionally, overseas R\&D was concentrated in developed, industrialized nations. Over the past decade, R\&D has not only become less geographically concentrated (see Figure 1), but there has been especially fast growth in less developed emerging markets (see Figure 2) like China and India.

One of the distinguishing features of the R\&D globalization phenomenon is its concentration within the software/IT domain. The increase in foreign R\&D on the firm side has been largely concentrated within software and IT-intensive multinationals. This concentration is mirrored on the country side; if we consider patent stocks as a mirror of a country's national innovative capacity and specialization (Furman, Porter, and Stern 2002), new R\&D destinations such as India, China, and Israel look very different in the types of innovative activity being done there than older R\&D destinations such as Germany, France, the UK, Canada, and Japan (see Figure 3). While the patent stocks of older R\&D hubs still tend to specialize in areas like mechanical engineering and pharmaceuticals, the patent stocks of countries like India and Israel clearly are specialized in software.

In this paper we will document three important phenomena: (1) the globalization of R\&D by US MNCs, (2) the growing importance of software and IT to firm innovation, and (3) the rise of new R\&D hubs, and the differences in the type of activity done there. Furthermore, we will argue that these are not separate phenomena but in fact are closely related. We argue that the shortage in software/IT-related human capital resulting from the large IT- and software-biased shift in innovation drove US MNCs abroad, and particularly drove them abroad to "new hubs" with large quantities of STEM workers who possessed IT and software skills. Our findings support the view that the globalization of US multinational $\mathrm{R} \& \mathrm{D}$ has reinforced the technological leadership of US-based firms in the information technology domain (Arora, Branstetter, and Drev 2013). They also point to the possibility that multinationals' ability to access an increasingly global talent base could support a high rate of innovation even in the presence of the rising (human) resource cost of frontier R\&D (Bloom et al. 2017; Jones 2009).

\section{The Globalization of R\&D}

Official data published by Bureau of Economic Analysis ${ }^{1}$ indicate that U.S. multinationals, as a group, have become increasingly R\&D-intensive. From 1999 through 2014 (the most recent BEA benchmark survey year), U.S. multinationals' global R\&D expenditure grew at an average annual rate of $5.6 \%$, substantially faster than growth in US multinational employment (2.1\%). Moreover, the distribution of this R\&D investment across countries and industries is changing rapidly. Between 1999 and 2014, the R\&D expenditure of the foreign affiliates of U.S. firms almost tripled, with particularly fast growth in emerging markets like China and India. Just during the years between 2004 and 2014, the R\&D expenditure of U.S. multinationals' foreign affiliates in China grew by a factor of 4 and expenditures grew in India by a factor of 25. In industries like computers and electronic products, the ratio of overseas $R \& D$ expenditure to domestic R\&D expenditure has grown from 10 percent in 1999 to nearly 20 percent in 2014. In high-tech services industries, the ratio has grown even faster -- R\&D expenditures by overseas affiliates in professional, scientific and technical services increased by more than a factor of eighteen between 1999 and 2014, and the ratio of overseas R\&D to domestic R\&D for multinationals in this industry has gone from under 10\% in 1999 to over 40\% in 2015.

The growth in US MNC foreign R\&D is on both intensive margin and on the extensive margin, with an average firm conducting R\&D in many more places than before, as shown in Figure 1. In 1989,

\footnotetext{
${ }^{1}$ https://www.bea.gov/iTable/index_MNC.cfm
} 
just five countries - the UK, Germany, Japan, France, and Canada - comprised 74\% of all foreign US MNC R\&D. By 2014, these same five countries made up only $43 \%$ of all foreign R\&D. The emergence of a host of "new hubs" - with Israel, India, and China particularly striking (see Figure 4) - and the corresponding relative decline in the relative importance of the traditional R\&D hubs, has fundamentally changed the foreign R\&D landscape.

These trends raise some questions: What motivates multinationals to conduct overseas $R \& D$, and how has this changed over time? What are the factors that influence the choice of location for R\&D? How can we explain the shift towards conducting overseas R\&D in developing countries?

An extensive literature has examined the phenomenon of overseas $R \& D$ and the motivations behind it. A thorough review of this literature can be found in Hall (2010) and Shu and Steinwender (2018), but we briefly examine two of the most widely-discussed and more relevant motivations here: access to local markets, and access to specialized knowledge.

Early papers (e.g. Hirschey and Caves 1981; Mansfield, Teece, and Romeo 1979; Ronstadt 1977) argued that the dominating rationale for overseas $R \& D$ expenditure was market-driven; multinationals wanted $R \& D$ units abroad to help adapt existing products better to local (preferably large) markets. Large host country markets and the presence of lead consumers are still described as a primary force driving overseas R\&D in the literature (e.g. von Zedtwitz and Gassmann 2002; Odagiri and Yasuda 1996; Edler, Meyer-Krahmer, and Reger 2002).

Although access to large markets is still a major, if no longer dominant, reason for placing R\&D units overseas, researchers soon started to observe that customization did not completely account for all foreign R\&D. It was during this time that the "knowledge-seeking" motivation emerged in the literature (e.g. Walter 1999; Florida 1996; Le Bas and Sierra 2002). The dominant view in the literature became that a major role of overseas R\&D was to tap into global sources of innovation for the whole multinational's benefit, and that it was a way for multinationals to maintain competitive advantage by taking advantage of different expertise around the world (e.g. Zander 1999; Chung and Alcácer 2002; Alcácer 2006; Alcácer and Chung 2007; Berry, 2014; Berry and Kaul, 2015). Global R\&D units were now involved not just in adaptation, but also in original product development and in sophisticated basic research.

The knowledge-seeking rationale behind conducting foreign $R \& D$ suggests that the knowledge assets of the host country are an important factor in a multinational's choice of R\&D location. In particular, a host country's supply of qualified, high-skilled personnel, and particularly the supply of personnel with unique talents, is regularly described in the literature as one of the central drivers of globalized R\&D (e.g. Thursby and Thursby 2006; Siedschlag et al. 2013; Serapio and Dalton 1999; Hall 2010). In addition to human capital, multinationals are concerned with the technological structure and the specialized knowledge stock of potential host countries, particularly for placement of knowledgeaugmenting R\&D labs (e.g. Hegde and Hicks 2008; Siedschlag et al. 2013; Florida 1996). Regardless of the exact conceptualization of knowledge-seeking R\&D in the literature, the common notion is one in which multinationals are tapping into a foreign knowledge resource that is more advanced than what they possess at home. An R\&D operation established in the host country provides the parent firm access to this superior knowledge, and therefore, knowledge-seeking R\&D is generally seen as a phenomenon concentrated in the most advanced industrial economies.

While the literature's understanding of the motivation behind and the management of R\&D in developed countries, as described above, is fairly developed, it fails to explain two important features of the new foreign R\&D landscape: (1) the increase in foreign R\&D on the extensive margin, and (2) the 
increasing importance of developing markets like China and India ${ }^{2}$. In this paper, we offer a new explanation for the shift in the location of foreign R\&D that thus far has not been explored in the literature. Our new explanation is centered on the increasingly central role of IT and software as drivers of invention across a broad swath of technical domains, and it stresses the importance of a global shortage of engineers with the basic skills required to add IT- and software-driven functionality to new products and service. As IT and software became more important, US multinationals moved some of their R\&D into national labor markets where engineers with these basic skills were relatively abundant. The movement was not primarily motivated by the desire to tap superior foreign knowledge in these domains - the conventional goal of knowledge-seeking $\mathrm{R} \& \mathrm{D}$ - but rather by the desire to incorporate local engineers with basic skills into a global R\&D network in which those basic skills were in short supply.

Correlations of IT/software intensity and foreign innovative activity provide some motivating evidence for this supposition, which we will expand upon in the rest of this paper. Figure 5 shows a scatterplot of a positive correlation between US MNC R\&D aggregate activity in a country, obtained from Bureau of Economic Analysis (BEA) aggregate data, and a country's software or IT hardware intensity ${ }^{3}$, conditioning on country fixed effects, and Figure 6 shows a scatterplot of a positive correlation between US firm IT and software intensity ${ }^{4}$ and their innovative activity in emerging markets ${ }^{5}$. These two graphs together suggest that foreign R\&D is most pronounced in IT/software-intensive countries, and that it is most intensively done by IT/software-intensive firms. Why? In the rest of this paper, we will argue (1) that the modularity of IT/software allows multinationals to conduct R\&D in more places than was previously possible, and (2) that the shift toward increasing reliance on IT/software in new invention is driving MNCs abroad in search of scarce talent.

\section{What is Special about IT/Software?}

There has been a systematic shift in the nature of new innovation toward more intensive use of software, both in IT industries and in more traditional manufacturing industries such as autos and auto parts, aerospace and defense, medical devices, and pharmaceuticals (Arora et al. 2013; Branstetter, Drev, and Kwon 2018). One way to think about this technological trend is by considering software through the lens of general purpose technologies (GPTs) (Bresnahan and Trajtenberg 1995; Helpman and Trajtenberg 1998), which are broadly characterized by their potential for pervasive use across most sectors, by their potential for improvement over time, and by their technological dynamism (a GPT should make it easier to invent).

\footnotetext{
${ }^{2}$ The increasing importance of developing economies has not been completely ignored in the literature. Alcácer and Zhao (2012), Zhao (2006), and Macher and Mowery (2008), to give some examples, have considered the changing foreign R\&D landscape, but the motivations behind the changing landscape have not been the focus of their work.

${ }^{3}$ We define a country's software or IT hardware intensity as the share of their cumulative USPTO citation-weighted patent stocks classified as software or IT hardware. We determine the location of a patent using inventor addresses; if an inventor lists their address on a patent in country $\mathrm{j}$, we define that patent as originating in country j. Software is defined using the Arora, Branstetter, and Drev (2013) methodology, and IT hardware is defined using the Hall, Jaffe, and Trajtenberg (2001) NBER technology classification. We define IT hardware as encompassing the following NBER technology classifications: 21 (communications), 22 (computer hardware and software), 23 (computer peripherals), 24 (information storage), 41 (electrical devices), and 46 (semiconductor devices). ${ }^{4}$ US firm IT and software intensity is measured as the firm's USPTO software or IT hardware patent stock, with software and IT hardware patents classified in the same way as described for country IT or software intensity. ${ }^{5}$ We define innovative activity in emerging markets as the proportion of its USPTO patents with an inventor from a non-high-income country, as classified by the World Bank. High-income countries as defined by the World Bank include: ABW, AND, ARE, UAS, AUT, BEL, BHS, BMU, BRN, CAN, CHE, CYM, CYP, DEU, DNK, ESP, FIN, FRA, FRO, GBR, GRC, GRL, GUM, HKG, IRL, ISL, ISR, ITA, JPN, KWT, LIE, LUX, MAC, MCO, MLT, MNP, NCL, NLD, NOR, NZL, PRT, PYF, QAT, SGP, SVN, SWE, TWN, USA, VIG
} 
Branstetter, Drev and Kwon (2018) point out that significant improvement in manufactured goods before the 1980s generally required expensive and complicated physical transformations in the mechanical, electronic, or chemical workings of the products. By the 1990s, however, increasingly powerful (and cheap) standardized microprocessors, electronic control systems, and sensors enabled a broader range of goods to alter their operations in response to changing conditions, so long as there was software to direct these electronic brains. This provided a new software-based approach to the enhancement of product functionality that was often cheaper and more powerful than traditional engineering methods. The salience of software as a pervasive driver of innovation has been further enhanced by the growing application of artificial intelligence (AI) and machine learning (ML) to a broad array of products and services.

The other defining feature of software and information technology is modularity. Baldwin and Clark (1997) define modularity as "building a complex product or process from smaller subsystems that can be designed independently yet function together as a whole”, and they note in a later piece (Baldwin and Clark 2004) that two of the primary purposes of modularization from an engineering perspective are "to make complexity manageable" and "to enable parallel work". Bresnahan (1998), among others, describes how innovation in the IT sector became dramatically more "modular" in the sense of Baldwin and Clark over the course of the 1980s and 1990s. Whereas an earlier generation of IT invention had been dominated by vertically integrated producers like IBM, who created all the constituent parts of a new computer, the rise of standard computer architectures and component interfaces in the late 1980s and early 1990s allowed for a vertical disintegration of hardware and software product development across multiple firms and multiple regions.

Conversations with industry practitioners confirm that software has become especially "modular" in this sense. The development of higher level computing languages brought with it the early creation of vast libraries of standard routines that could be recombined to produce an almost infinite variety of software-driven product features. Software in an internet age can be quickly and easily transmitted around the world - far more easily than the physical components that are still critical in many domains of engineering - and software components developed in a remote site can be quickly tested and integrated into larger systems. The internet and advanced information technology have created the possibility of long-distance R\&D collaboration in real time that could not have been managed in earlier eras. This allows foreign "raw talent" to be more effectively integrated into international research teams than in the past. While this general increase in the effectiveness of international collaboration applies to all disciplines, the inherent modularity of software and IT design allow these domains to exploit international collaborative opportunities more easily. These characteristics of software and information technology allow firms to (1) do R\&D abroad more easily, and (2) do R\&D in many locations at once.

\section{The Growing Importance of Software and IT for Firms}

Software patents have been growing in importance since the 1990s; as Figure 7 shows, the share of all USPTO patents that are software grew from 5\% in 1990 to nearly $40 \%$ by 2015 . This growth is in aggregate, across all classes and firms, but in some industries, it is even more striking. More important than the simple fact that software-intensity in innovation is increasing is the evidence suggesting that firms that do not invest in software and IT are actually left behind. Arora, Branstetter, and Drev (2013) show that in the IT industry, the success of American IT firms relative to Japanese IT firms can be at least partially explained by their difference in software intensity. Japanese IT firms that were less softwareintensive were actually less productive than their American counterparts; failing to become more software-intensive can be harmful to a firm. Branstetter, Drev, and Kwon (2018) document that the importance of software is not limited to the IT sector; they show that four traditional manufacturing industries (autos and auto parts, aerospace and defense, medical devices, and pharmaceuticals) have also experienced a software-biased shift in the trajectory of innovation. Furthermore, they show that the firms 
that took a more software-intensive approach to innovation outperformed their less software-intensive peers.

Information technology's growth in importance began earlier than software's, as shown in Figure 7, and it has also grown rapidly over time. As the argument laid out in the preceding paragraphs makes clear, this was logically necessary - the software "minds" increasingly embedded in new products and services require IT hardware "bodies" through which they can impact and enhance user experience. The expanding reach of software therefore relies on and is, in part, driven by complementary innovation in IT hardware. This argument stresses the growing importance of IT and software capabilities in the creation and refinement of new products. There is also a body of evidence pointing to the importance of effective IT use in making production more efficient across the economy (e.g. Brynjolfsson and Hitt 1995; Brynjolfsson and Mcelheran 2015; Syverson 2011), and this has also helped drive IT patenting to high levels.

The increased importance of IT and software intensity in innovation has led to growth in demand for software- and IT-related human capital. In fact, Arora, Branstetter, and Drev (2013) argue that it was human resource constraints that prevented Japanese firms from being able to adapt to the software-biased shift in IT innovation; the openness of the US's labor markets to foreign software engineers allowed them to adjust better. In this paper, we suggest that US multinationals, in addition to hiring more STEM immigrants, went abroad to locations with large quantities of STEM workers and competencies to address the shortage in software/IT-related human capital resulting from the large IT- and software-biased shift in innovation.

\section{Foreign Human Capital in IT and Software}

Bound et al. (2015) document the expansion in the representation of high-skill foreign-born IT workers in parallel with the rising importance of IT in the US. We highlight a few of the more striking trends that they document here, but a more thorough examination can be found in their paper. According to the National Survey of College Graduates, the IT workforce, made up of programmers, computer scientists, and electrical engineers grew by 112\% between 1993 and 2010, while the overall workforce only grew by $70 \%$. The foreign share of IT workers grew from 16\% in 1993 to 32\% by 2010 .

These changes suggest an extremely large increase in demand that was partially met by importing talent from abroad, through mechanisms like the H-1B program. A closer examination of the countries supplying this talent suggests that the supply of technically skilled workers is abundant in many of the same countries - notably India and China - where we see a parallel increase in US MNC foreign R\&D activity. Applications for Indians made up 62\% of new H-1B visa applications in $2016^{6}$, and Indian and Chinese students combined made up $18 \%$ of doctorates in science and engineering from US universities in $2016^{7}$, and this share is even larger for some key disciplines. If we view the large number of Indian and Chinese students pursuing graduate education at American research universities as the extreme right tail of a distribution of science and engineering talent, most of which remains at home, then this suggests a massive amount of software- and IT-trained human capital available in China and India. The abundant supply of engineering and technology graduates in emerging economies has also been documented in Arora and Gambardella (2005a) and Arora and Gambardella (2005b).

The evidence also suggests that the talent resident in key emerging markets has been available for hire at wages well below those prevailing in the United States. In Figure 8, we show average compensation per worker for US multinationals across different countries, using publicly available

\footnotetext{
${ }^{6}$ According to USCIS Fiscal Year 2016 Annual Report to Congress: "Characteristics of H-1B Specialty Occupation Workers."

${ }^{7}$ National Science Foundation, National Center for Science and Engineering Statistics, Survey of Earned Doctorates
} 
Bureau of Economic Analysis data ${ }^{8}$. When we look at average compensation per employee in aggregate, we see that the US is in the middle of the country distribution. However, if we consider IT-specific industries ${ }^{9}$ like Electrical Equipment Appliances and Components or Computers and Electronic Products, the average compensation per employee for employees at US headquarters as compared to employees at a foreign affiliate is much higher. And notably, India and China are among the cheapest employees for US MNCs in these industries. These average compensation numbers necessarily aggregate across multiple functions within U.S. parents and affiliates - the wages of skilled R\&D personal are likely to be relative high in both the U.S. and abroad. Nevertheless, these numbers are clearly consistent with the prevailing view that "raw" engineering talent of high quality is available in large quantity and at relatively low prices in emerging markets - especially India and China.

Within many US multinationals, the rise in demand for IT and software engineers was especially acute and the supply of foreign engineers in these disciplines was especially abundant. This leads to one of the central findings of the paper - software-intensive and IT-intensive US multinationals rapidly expanded their R\&D in emerging markets where high-quality human capital was available in relatively abundant supply and at relatively low wages. Referring again to Figure 6, we see a striking correlation between US firm IT and software intensity and their innovative activity in emerging markets.

\section{The Role of Software and IT in the Rise of the New Hubs}

In sections I and II, we noted that foreign R\&D is no longer concentrated in what we called the “old hubs" of Germany, the UK, France, Japan, and Canada and now takes place in a multitude of countries around the world. While many countries have emerged as new R\&D destinations, we focus on three in particular - India, China, and Israel - which we call the "new hubs". These three countries (1) have seen among the fastest growth rates in foreign $R \& D(47 \%, 55 \%$, and $26 \%$ respectively since 1999) among all R\&D destinations, and (2) by 2015 made up 18\%, combined, of all foreign R\&D by US multinationals. No other new R\&D destination looms as large as these three in the new multinational landscape. Furthermore, the three countries are different enough that, while they share certain themes such as the strength of their IT-oriented human capital - they also highlight some of the heterogeneity that exists and should not be ignored across R\&D destinations.

As established in the globalization of R\&D section earlier, the assets of the host country are an important factor in a multinational's choice of R\&D location, and they can influence the types of innovative activity a multinational undertakes. Therefore, if we look at the type of multinational activity in the so-called "new hubs", we would expect to see specialization in IT and software. The graphs shown in Figure 3 illustrate that, as expected, the R\&D performed by US MNC affiliates in the "new hubs" of China, India, and Israel are concentrated in very different industries than in the traditional R\&D hubs. The industries of the affiliates doing R\&D in Germany, Japan, Canada, the UK, and France are concentrated in traditional manufacturing, while R\&D-performing affiliates in China, India, and Israel are in computer and electronic production manufacturing and professional, scientific, and technical services. Similarly, if we consider USPTO patenting by US multinationals in each country ${ }^{10}$, Figure 9 shows that software makes up the vast majority of patents in India and Israel.

Qualitative interviews with US multinationals conducting R\&D in India, Israel, and China, conducted in 2015 and 2016, highlight the unique resources that these countries offer, and underscore the idea that raw human capital has been a significant motivator in US MNC decisions to open R\&D facilities in these locations.

\footnotetext{
${ }^{8}$ https://www.bea.gov/iTable/index_MNC.cfm

${ }^{9}$ Classified using the industry of the foreign affiliate.

${ }^{10}$ As identified by the address of the inventors on the patents.
} 


\section{Case Study: India}

The abundance in India of relatively low-cost software engineers ${ }^{11}$ was repeatedly emphasized as a reason for U.S. multinationals to expand their R\&D activity in that country. India's success in exporting software and business process outsourcing services established the quality of Indian software engineers, and U.S. firms in these service sectors were especially aggressive at shifting some research and development activities to India - largely because of that country's growing role, professional services is the U.S. industry with the most globalized $R \& D$. In recent years, the ratio of $R \& D$ performed by foreign affiliates in professional services relative to that undertaken by the U.S. parents is over $40 \%$, and India makes up an important piece of that. Because software has increasingly become a critical input to innovation across the entire product space, manufacturers have joined services firms in meeting some of their demand for software engineering skill with Indian labor.

The Indian case also casts a particularly strong light on the difference between the "knowledgeseeking" motivation described in the literature and the search for cheap software engineers we highlight here. U.S. multinationals were not investing in India to tap new technologies developed autonomously by indigenous Indian firms or to learn frontier science from pioneering Indian academic institutions. For the most part, the innovative capabilities of indigenous Indian firms are still viewed as quite limited compared to those of the multinationals resident in India. So, one can draw a distinction between the knowledge-seeking FDI explored in the empirical literature of the 1990s and early 2000s and what seems to be happening in India. Multinationals are not seeking to tap into an indigenous body of knowledge, in the same way that they might have sought to tap into German chemical engineering capability or Japanese expertise in cutting edge consumer electronics in earlier decades. Instead, many multinationals were tapping "raw” Indian talent and integrating that talent into multinational R\&D systems in which a significant amount of the intellectual leadership and direction still came from outside India (Branstetter, Glennon, and Jensen 2018). In the more mature and developed R\&D centers, Indian staff are beginning to exert more intellectual leadership in some domains, but there is still a gap between indigenous and multinational innovation. Our interviewees emphasized the importance of a common language and the role of the Indian diaspora in the United States in successfully integrating Indian talent.

\section{Case Study: Israel}

The attraction of human capital was also a major theme of our interviews in Israel, although the nature and genesis of that human capital differed in significant ways from the Indian case. Universal conscription of the Jewish population places much of the nation's human capital endowment under the authority of the military, and a rigorous battery of tests sorts the most intellectually gifted recruits into elite groups like Unit 8200, a signals intelligence unit that is often compared to America's National Security Agency. At a formative stage in their lives, young Israelis assigned to these units receive intensive exposure to high level computer science and electrical engineering skills, which often exerts a profound influence on their education and career choices after their return to civilian life. Almost by accident, the Israelis have created a unique set of institutions that steers a disproportionate fraction of their most gifted citizens into computer science related careers, and the stock of veterans of these elite units was growing to significant levels just as the global trajectory of innovation shifted in a way that made software more central to nearly every domain of technological innovation. Israeli per capita GDP still lags that of the U.S, but Israeli wages are not cheap. Nevertheless, MNCs are investing because the quality of Israeli human capital is distinctively high. Not surprisingly, domains of Israeli strength like cybersecurity and machine vision often have a connection to military or intelligence functions. Some Israeli firms in these domains have gone on to become major global leaders in their fields, and previous

\footnotetext{
${ }^{11}$ Arora and Gambardella (2006) have described the sequence of developments that enabled India to produce such a large number of software engineers.
} 
IPO success helped induce an impressive flow of energetic and creative Israeli start-ups. However, acquisition by a U.S. multinational is now a far more likely outcome for these start-ups than an IPO.

These acquisitions and the successful integration of the firms into the R\&D operations of U.S. multinationals are partly enabled, once again, by a prominent diaspora in the United States. The interaction between Israeli and American financiers, scientists, and engineers is quite intense, especially when scaled to the size of the Israeli economy. Many Israeli senior managers of U.S. MNC R\&D operations in Israel have family connections to the United States, received part of their education at an American university, and spent years in Silicon Valley before returning to Israel. On the other side, many prominent American managers, venture capitalists, and scientists have personal/family ties to Israel. American multinationals are investing in Israel to take advantage of distinctive Israeli competencies, but these competencies have been jointly developed by Israel's unique institutions, American firms, and the Israeli corporate entities they have established or acquired, rather than wholly developed by a cluster of indigenous firms.

\section{Case Study: China}

Multinational investment in China is a more complex phenomenon. Interviewees maintained that the scale, cost, and quality of Chinese engineering talent was an important draw, and that Chinese engineers were involved in international teams creating inventions for the global market. Unlike in Israel or India, though, it was apparent that multinationals conducting R\&D in China were seeking to (re)design Western technology for a Chinese market that is large, rapidly growing, but distinctive and different from high-income Western markets. In this new hub, there are clearly some older motives (market adaptation) for MNC R\&D investment, as well as the newer ones we stress in this paper. It is also the case that Chinese $R \& D$ is more hardware-focused than Israeli or Indian $R \& D$, reflecting China's emergence as the leading producer and exporter of IT hardware and components. As in Israel and India, the Chinese diaspora in the United States played an important role in helping U.S. multinationals recruit talent and navigate the complex business environment of contemporary China.

The presence of strong diasporas for all three of our new hubs is significant when considering findings from Kerr and Kerr (2015) and Foley and Kerr (2013), which show that the ethnic composition of a firm's inventors is associated with increases in the share of that firm's affiliate activity in countries related to that ethnicity.

\section{Empirical Evidence}

The analysis thus far has relied on aggregate trends and correlations to argue that an important but thus far understudied - factor in a firm's decision to conduct R\&D abroad and in the rise of new R\&D hubs is the role of information technology and software. In this section, we will provide some additional econometric analysis that adds support to the argument that the shift toward increasing reliance on IT/software in new invention is driving MNCs abroad in search of scarce talent.

\section{VIIa. Data}

We use a combination of two sources of data to generate a unique panel dataset for analysis of US multinational innovative activity abroad. The first is the Bureau of Economic Analysis's (BEA) annual surveys on U.S. Direct Investment Abroad. BEA is under a congressional mandate ${ }^{12}$ to track investment into and out of the United States, and as such, their data comprise the most comprehensive available data on US multinational activity abroad. The database contains financial and operating characteristics of both the US parent companies and their foreign affiliates, including R\&D expenditures, which is the primary

\footnotetext{
${ }^{12}$ By the International Investment and Trade in Services Survey Act. The data are collected for the purpose of producing publicly available aggregate statistics on the activities of multinational enterprises.
} 
variable of interest for this paper. We constructed a panel dataset of this activity from 1989 through $2014^{13}$.

Each firm may report on a consolidated basis for multiple affiliates in the same country under certain conditions ${ }^{14}$. Therefore, rather than conducting analysis at the affiliate level, we aggregate all foreign affiliate activity up to the country level for a given firm for a given year.

The second source of data is US Patent and Trademark Office (USPTO) patent data, obtained using the PatentsView database ${ }^{15}$, and includes all utility granted patent applications through August 2017. We restrict our analysis to USPTO patents, rather than JPO or EPO patents, for three primary reasons: (1) our sample is US multinationals, (2) the use of USPTO patents ensures a common standard that is close to or at the global technological frontier, and (3) the use of USPTO patents allows a comparable measure across countries. Patents are a very imperfect measure of innovation; there is heterogeneity across countries, firms, and industries in the propensity to patent. However, patenting does reflect an important piece of a country's innovative output, and it is highly correlated with other measures of innovation. Because obtaining a patent from USPTO is costly and requires that the patent is for a novel invention, the use of USPTO patents helps to ensure that the counted inventions are close to the technological frontier. It also ensures that a common standard is being applied. While this measure of innovation is not ideal, we believe it is the best available measure of innovation that is consistent for both cross-country comparison and across-time comparison. Furman, Porter, and Stern (2002) provide further support for our use of patenting as a comparison measure of a country's innovation; they provide an extensive overview of other measures of a country's national innovative capacity and come to the conclusion that patents are "the most concrete and comparable measure of innovative output over countries and time”.

There are no numerical identifiers that exist in both the BEA data and the USPTO patent data, so we matched the two databases using firm names. We conducted several rounds of fuzzy matching between BEA multinationals and patent assignees using the "reclink2" Stata command, followed by manual verification to ensure the generated matches were correct. If a firm appeared in the BEA data but not in the patent data in a given year, we assumed that it did not apply for any patents in that year.

Following the prior literature, we consider the patent inventors' country of residence as the country where an innovation takes place, and we consider a patent as having originated from a foreign country if any of its inventors list their address as from that country. Using these data, we are able not only to see whether a firm is patenting in a country, but we are also able to see the firm's R\&D expenditures there using the BEA data. This means that we are uniquely able to eliminate instances where there are patents that appear to originate in a country where there is no R\&D-performing affiliate. Our final dataset is at the firmcountry-year level and varies across firms, countries, and time.

\section{VIIb. Measuring software and IT intensity}

The two key independent variables are multinational software intensity and country software intensity. We define both using citation-weighted patent stocks, within which patents are classified as software- and/or IT hardware-related.

\footnotetext{
${ }^{13}$ The most extensive data are collected in benchmark years: 1989, 1994, 1999, 2004, 2009, and 2014. The reporting requirement threshold varies by year, size of the affiliate, and the parent's ownership stake. BEA estimates values of some variables of some affiliates in non-benchmark years in order to estimate a consistent universe across years. We only use the reported data in this paper.

${ }^{14}$ These conditions are that the affiliates operate in the same country and same industry classification or are integral parts of the same business operation.

${ }^{15}$ http://www.patentsview.org/web/
} 


\section{Defining software and IT hardware patents}

Software is defined in the same way as in Arora, Branstetter, and Drev (2013) and Branstetter, Drev, and Kwon (2018). This methodology uses a set of keywords (e.g. “computer program” or "software") associated with software-based technologies as defined by Bessen and Hunt (2007) to define one set of patents as software, and uses a narrow set of IPC categories as defined in Graham and Mowery (2003) to define another set. The final population of software patents is defined as the union of these two sets of patents. IT hardware is defined using the Hall, Jaffe, and Trajtenberg (2001) NBER technology classification, where all patents classified in the following categories are marked as IT hardware-related: 21 (communications), 22 (computer hardware and software), 23 (computer peripherals), 24 (information storage), 41 (electrical devices), and 46 (semiconductor devices).

\section{Country software/IT intensity}

We use cumulative USPTO citation-weighted patent stocks as a measure of country-level innovative capacity, following the prior literature (Chung and Yeaple 2008; Furman et al. 2002), but we disaggregate these stocks using the software and IT hardware definitions described above. When we construct country software-specific or IT hardware-specific knowledge stocks, we include all patents filed at the USPTO by foreign inventors, with the exception of the relevant multinational. This means that the country stocks are firm-specific; for a given firm-country-year observation, the country's patent stocks in that year will exclude the firm's patenting in that country for that year to reduce endogeneity.

Following the prior literature, we utilize USPTO data rather than host country patent agency data for several reasons. First, filing for a U.S. patent is costly, so we would expect firms to only file patents in the U.S. when they are more valuable. Second, the use of USPTO patents ensures a common standard that is close to or at the global technological frontier. Finally, the use of USPTO patents allows a comparable measure across countries. While this measure of innovation is not ideal, we believe it is the best available measure of innovation that is consistent for both cross-country comparison and across-time comparison.

We construct a moving cumulative stock of citation-weighted patents to represent the knowledge stock of a country in a particular technology area, where we use the yearly flow in 1980 to begin and then add yearly patent flow, depreciating the previous year's stock by $20 \%$ following Chung and Yeaple (2008). Our final definition of IT or software intensity of a country is the share of the software and/or IT stock of all USPTO citation-weighted patents applied for in a given country in a given year, minus the relevant firm. This can have three forms: share of software stock only, share of IT hardware stock only, or the union of the two. To reduce volatility and noise in the shares variable, we restrict our sample to include only countries with at least a 500 patent stock. We multiply the shares by 100 for ease of interpretability.

\section{MNC software/IT intensity}

Our definition of MNC software/IT intensity is very similar to the country-specific definition, with one major exception: instead of considering shares, we consider the stock of software and/or IT hardware citation-weighted patent stocks. Shares are too noisy since many firms either do not patent or patent very little. We define the IT or software intensity of a firm as the software and/or IT stock of all USPTO citation-weighted patents applied for by that firm (in any location) in a given year.

\section{VIIb. Empirical Approach and Results}

We first regress the log of foreign R\&D expenditures on our measure of country software intensity, controlling for country fixed effects:

$$
\ln \left(\mathrm{rd}_{\mathrm{jt}}\right)=\beta_{0}+\beta_{1} \text { ShareITSoftware }_{\mathrm{jt}}+\alpha_{\mathrm{j}}+\epsilon_{\mathrm{jt}}
$$


Where $\mathrm{j}$ indexes countries, $\mathrm{t}$ indexes years, ShareITSoftware is our measure of country-level software or IT-intensity, and the dependent variable is the total foreign R\&D conducted in country $\mathrm{j}$ in year $\mathrm{t}$ by all US multinationals, as reported in aggregate BEA statistics. Figure 6 graphs these results using an AV plot; it shows the correlation between ShareITSoftware and foreign $R \& D$ after having removed country fixed effects, and shows a strong positive correlation. These results provide strong supportive evidence for that idea that US multinationals are increasing their R\&D expenditures in countries that specialize in IT hardware or software.

However, this model is only on publicly available, aggregate data. Our primary regression specification leverages the firm-country level microdata constructed using BEA data and patent data. In this specification, we regress the change in overseas R\&D on country and MNC software-orientation in an initial period, to see whether higher software intensities at the firm and country level are predictive of increased foreign R\&D by those firms in those countries at a later period. These estimates are not causal, but they provide some suggestive evidence that increasing reliance on IT or software in innovation is driving multinationals to do more R\&D abroad. The model is as follows:

$$
\begin{gathered}
\ln \left(\operatorname{rd}_{\mathrm{ij2014}}\right)-\ln \left(\mathrm{rd}_{\mathrm{ijs}}\right)=\beta_{0}+\beta_{1} \text { HiMNCSoftware }_{\mathrm{is}}+\beta_{2} \text { CtrySoftware }_{\mathrm{ijs}}+\beta_{3} \text { HiMNCsoftware }_{\mathrm{is}} \\
* \text { CtrySoftware }_{\mathrm{ijs}}+\mathrm{X} \delta+\epsilon
\end{gathered}
$$

where i indexes the multinational, $\mathrm{j}$ indexes the country, and $\mathrm{s}$ is a base year (1994, 1999, or 2004). We split multinationals into two categories: High software intensity, and low software intensity, represented by a dummy variable equal to one if the MNC belongs to the high software intensity group in that year and zero otherwise. High software intensity is measured using the $90^{\text {th }}$ percentile of MNC software citation-weighted patent stocks in that year. $\mathrm{X}$ is a set of controls that include the number of over 25 yearolds that have completed a tertiary education ${ }^{16}, \ln$ (GDP in current USD), GDP growth ${ }^{17}$, the reporter's R\&D expenditures in the US in the base year, the total global sales of the multinational as a proxy for size in the base year, the mean effective tax rate in the country ${ }^{18}$, and the average compensation per worker ${ }^{19}$. Standard errors are clustered at the firm level. We make two other sample modifications for these regressions: (1) we remove the finance and insurance industry, since banks were only required to start reporting in the 2000s, and (2) we removed countries that had fewer than 100employees at all foreign affiliates across all firms.

We are especially interested in $\beta_{3}$, the coefficient on the interaction term; we would expect for the software intensity of a country to matter the most for multinationals that are more software-intensive. We would not expect the software intensiveness of a country to matter for multinationals who are not software-intensive. Therefore, we expect $\beta_{3}>0$. We consider two versions of the dependent variable, with the goal of examining both the intensive and the extensive margin. The first set of regressions uses the logged differenced R\&D expenditures ${ }^{20}$ by firm i in country j between 2014 and the base year (1994,

\footnotetext{
${ }^{16}$ From the Barro-Lee human capital dataset.

${ }^{17} \mathrm{GDP}$ and GDP growth are both from the World Bank.

${ }^{18}$ Calculated using BEA data. We took all affiliates with positive net income that reported paying income tax, then computed the ratio of taxes paid to the sum of taxes paid and net income. Finally, we took the mean within each country/year, checking to make sure the rates are between 0 and 1 . These rates are not affiliate-specific but country/year-specific.

${ }^{19}$ Calculated using BEA data. We took all affiliates with positive R\&D expenditures, then divided compensation by number of employees for those foreign affiliates. We then took the mean within each country/year. These rates are not affiliate-specific but country/year-specific.

${ }^{20}$ We add one to the R\&D expenditures to ensure that observations where R\&D expenditures are equal to zero are not dropped.
} 
1999, 2004) as the dependent variable. This measure captures both the intensive and extensive margin at once. Table 1 shows the results of this model for all three years ${ }^{21}$.

As expected, regardless of the base year, the interaction coefficient between MNC software intensity and country software intensity is positive and statistically significant ${ }^{22}$, and this is robust to the inclusion of a whole host of controls. At first glance, the fact that the country software intensity coefficient is negative and the MNC software intensity coefficient is either not statistically significant or is positive and only slightly statistically significant seems surprising. However, these results make more sense once we consider them alongside the interaction term; according to our hypothesis, the growth in overseas R\&D for software-intensive multinationals should occur in software-intensive countries. Nonsoftware-intensive countries will hold much less appeal for software-intensive multinationals. Similarly, we would not expect to see growth in R\&D from non-software-intensive multinationals in softwareintensive countries ${ }^{23}$. The interaction term demonstrates that it is the combination of software intensity on both the multinational and country sides that is significant. Furthermore, while the coefficients may appear small, some examples demonstrate that they indicate quite large predicted changes. If we take the example of India, a highly software intensive MNC will have a 58\% larger change in R\&D than a nonsoftware intensive MNC between 2004 and 2014. To give another example, if we were to give Mexico the software intensity of India, it would be predicted to see a $26 \%$ increase in R\&D between 2004 and 2014 by software-intensive MNCs.

We then break this apart to examine whether the correlation appears to be stronger on the extensive or intensive margin. In the extensive margin case, the dependent variable is equal to one if firm i conducted zero R\&D in country $\mathrm{j}$ in the base year $(1994,1999$, or 2004) and had positive R\&D expenditures in 2014, and it is equal to zero if either the firm never conducted R\&D or if the firm always conducted $R \& D^{24}$. Note that the extensive margin covers two cases: (1) firm i had zero operations of any kind in the base year and opened an R\&D-performing foreign affiliate later, or (2) firm i had a foreign affiliate in country $\mathrm{j}$ in the base year but did not perform $R \& D$ there until later. We estimate this version of the model using a linear probability model, but it is robust to probit and logit models as well. Table 2 shows the results of the linear probability model for all three base years.

These results suggest that much of the increase in overseas R\&D that is correlated with MNC software intensity and country software intensity comes from the extensive margin, and particularly when considering growth from the 1990s to 2014. The results when 2004 is the base year are the weakest, but when we consider the intensive margin only, these become the strongest. The opposite is true for 1994, where the extensive margin results show the largest coefficient. Overall, we find that there is a strong positive correlation between the initial software intensity of firms and countries and the probability of those firms starting to conduct R\&D in those countries. We interpret the results as supportive evidence for the hypothesis that the increasing need for software in innovation for firms drove them abroad to open foreign R\&D-performing affiliates in countries with software expertise and human capital.

\section{Discussion}

Our analysis provides strong suggestive evidence that the increasing reliance on IT and software in innovation and the extensive endowments of specialized human capital in countries like India and

\footnotetext{
${ }^{21}$ Results for base year 1994 or 2004 can be found in the Appendix.

${ }^{22}$ Note that while the interaction coefficient is not statistically significant for the 1994-2014 timeframe, it is similar in magnitude to the other periods, but imprecisely estimated. The interaction coefficient for the other periods is positive and statistically significant.

${ }^{23}$ The foreign R\&D patterns are different from those found in the US by Forman, Goldfarb, and Greenstein (2016).

${ }^{24}$ There are some firms that stopped conducting R\&D abroad, went out of business, or closed a foreign affiliate. We coded these as zero in our baseline regressions, but also ran the regression without them as a robustness checks; the results are qualitatively the same.
} 
China induced US MNCs to conduct more R\&D in these locations. Our evidence is suggestive, not dispositive; we have not statistically proven the existence of a causal relationship between these factors, although we have built a case through interviews and descriptive analysis. We also acknowledge that other factors, including some of the motivations identified in the prior literature, have influenced the increase in $R \& D$ in the new hubs. A comprehensive analysis of these factors, together with an effort to identify the relative importance of the phenomena emphasized in this paper, is the subject of ongoing work.

We also want to highlight the significance of this work in the context of recent related research. Rising concern regarding the persistent productivity slowdown in the advanced industrial world is deepened by theoretical and empirical work suggesting that innovative effort in the most advanced economies is running into diminishing returns. Bloom et al. (2017) show that, even in disciplines with a high degree of technological opportunity, recent advances have required a significant increase in human inputs. The fascinating theoretical model created and tested by Jones (2009) provides a compelling rationale for both papers, one driven by the physiological limits of human cognition. Researchers and inventors are not born knowing the knowledge that accumulated before they began their careers. Instead, new cohorts of researchers must start from ignorance and acquire knowledge of the existing state-of-theart before they can contribute to it. As the foundation of existing knowledge grows, new researchers are forced by human limits to specialize in narrower domains, and research progress requires ever larger teams with growing coordination costs. An R\&D system limited to the research-capable population of a single country, even one as populous as the U.S., will inevitably run into diminishing returns. Indeed, the evidence of Jones (2009) and Bloom et al. (2017) suggests that the era of diminishing returns is already at hand. This gives sobering theoretical foundations for the grim view exposited by Gordon (2016) that the era of invention-driven growth in output and living standards has come to an end.

Of course, Freeman (2006) and others have noted the significant growth in university-trained scientists and engineers outside the advanced industrial world, but there is evidence to suggest that the rise in the raw numbers of scientists and engineers in places like India and China has not yet translated into large quantities of fundamental innovations created by indigenous companies. The skills required to coordinate teams of researchers in a way that yields breakthrough innovations take time to evolve.

But the global innovation networks that US multinationals are creating constitute a mechanism through which the raw talent of emerging markets can be connected to the coordinating skills and frontier research acumen of the world's most innovative multinationals. Evidence published elsewhere points to the possibility that the payoff of this kind of collaboration could be quite high (Branstetter, Li, and Veloso 2015). An infusion of millions of scientists and engineers could keep the Western innovation engine from stalling for a long time. The inventions produced from this international partnership could be widely shared, through the integrated global economy that has played such an important role in enabling the rapid growth and convergence to first-world living standards currently being experienced by India and China. The current paper suggests that multinationals are reconfiguring their global R\&D networks in a manner that aligns with the most significant technological opportunities and resource constraints they currently confront.

To the extent that the rapidly growing investments in global R\&D networks are rational, they provide a new reason for worry that policymakers around the world are rejecting globalization. If a greater globalization of $R \& D$ is required to maintain a flow of innovations in the domains where technological opportunity is greatest, then de-globalization could have severe consequences for the future trajectory of growth and living standards. These concerns are explored further in the next section.

\section{Conclusions and Policy Implications}

In this paper, we documented three important phenomena: (1) the increasing globalization of R\&D activity by US MNCs, (2) the growing importance of software and IT to firm innovation, and (3) 
the rise of new R\&D hubs, and the differences in the type of activity done there. We argued that these are not separate phenomena but in fact are closely related, and that the shift toward increasing reliance on IT/software in innovation is driving MNCs abroad in search of scarce talent.

Our findings have important implications for policymakers. First and foremost, they suggest that there is a constraint on the supply of IT and software human capital in the US, and that these human resource constraints are limiting the invention possibilities for U.S.-based multinational firms, even in the domains where innovative activity and technological opportunity seem to be at the highest levels. Global flows of investment, people, and ideas can help relax these constraints to some extent, through open immigration policies and liberal trade and FDI policies. When successful, these flows will not only benefit innovating multinationals but could also raise growth, productivity, and consumption possibilities around the world.

While we have not explored the impact of immigration in this paper in detail, existing evidence suggests that the openness of the US's labor market to immigrants in the 1990s allowed US-based firms to quickly adapt to the software-biased shift in technological opportunity, which brought with it an unexpected and sharp increase in demand for software engineers, by importing more software engineers at the height of the internet boom than the U.S. was training in its own universities. Arora, Branstetter, and Drev (2013) argue that Japanese firms were constrained in their ability to respond to this shift, as a result of their rigid and closed-off labor market, and that part of Silicon Valley's evident resurgence vis-àvis their Japanese competitors was based on American firms' greater access to immigrant talent.

Since the 1990s, however, the US's labor market has become more and more closed to immigration. Caps on high-skilled visas, like the H-1B visa program, have grown ever more restrictive, and preliminary evidence from Glennon (2018) shows that these restrictive high-skilled immigration caps drove U.S. MNCs to shift some of their R\&D to the places from which they had been recruiting immigrant engineers in an effort to address these constraints. Relatively liberal trade and FDI policies have allowed MNCs to address their human resource constraints by sourcing from abroad, but an open immigration regime for highly skilled workers would further ease this constraint. Finally, in addition to open immigration and liberal trade and FDI policies, the constraint on the supply of IT and software human capital in the US could be addressed with education policies that expanded the native IT and software human capital supply.

Second, we document a sharp rise in outbound FDI focused on R\&D at a time when political leaders in the United States and elsewhere have castigated foreign investment for weakening U.S. production, employment, and growth. In the context of this debate, our findings could suggest that investment in R\&D overseas is hollowing out or weakening R\&D capabilities at home. Even if greater $R \& D$ abroad improves the overall efficiency of the global $R \& D$ system, it could attract criticism if it degrades or undermines innovative efficiency as home. The exact degree of substitution or complementarity between overseas and home R\&D is the subject of ongoing research, but the results of Branstetter, Glennon, and Jensen (2018) and Macher and Mowery (2008) suggest that US inventors inside U.S. parent firms continue to play a central role in multinational R\&D operations, retaining a role as the central hub in a global R\&D network across virtually the entire spectrum of patent classes and technology domains, even as overseas R\&D grows. Arora and Gambardella (2005b) hold a similar view for the India case, arguing that the type of software offshored to India is software production rather than software design, which continues to be located in the US. This view is also supported by our own qualitative interviews. If overseas $R \& D$ is complementary to $R \& D$ at home, then public policies designed to constrain or tax outward FDI could lower the marginal product of home-based R\&D.

A more definitive answer to these public policy concerns will require a more detailed analysis of the impact of rising overseas $R \& D$ on the productivity of multinational firms' entire global R\&D networks, including the R\&D conducted at home in the U.S. Prior analysis has yielded ambiguous results, but this may reflect the degree to which foreign $R \& D$ operations take time to reach their full potential, a 
phenomenon explored further in Branstetter, Glennon, and Jensen (2018). A more complete productivity analysis that takes this into account is the subject of ongoing research efforts. 


\section{References}

Alcácer, Juan. 2006. "Location Choices Across the Value Chain: How Activity and Capability Influence Collocation.” Management Science 52(10):1457-71.

Alcácer, Juan and Wilbur Chung. 2007. “Location Strategies and Knowledge Spillovers.” Management Science 53(5):760-76.

Alcácer, Juan and Minyuan Zhao. 2012. "Local R\&amp;D Strategies and Multilocation Firms: The Role of Internal Linkages.” Management Science 58(4):734-53.

Arora, Ashish, Lee G. Branstetter, and Matej Drev. 2013. "Going Soft: How the Rise of Software-Based Innovation Led to the Decline of Japan's IT Industry and the Resurgence of Silicon Valley.” Review of Economics and Statistics 95(3):757-75.

Arora, Ashish and Alfonso Gambardella, eds. 2005a. From Underdogs to Tigers: The Rise and Growth of the Software Industry in Brazil, China, India, Ireland, and Israel. Oxford University Press.

Arora, Ashish and Alfonso Gambardella. 2005b. "The Globalization of the Software Industry: Perspectives and Opportunities for Developed and Developing Countries.” Innovation Policy and the Economy 5:1-32.

Baldwin, C. Y. and K. B. Clark. 1997. "Managing in an Age of Modularity.” Harvard Business Review 75(September):84-93.

Baldwin, Carliss Y. and Kim B. Clark. 2004. "Modularity in the Design of Complex Engineering Systems.” Complex Engineered Systems Understanding Complex Systems (January):175-205.

Le Bas, Christian and Christophe Sierra. 2002. “'Location versus Home Country Advantages' in R and D Activities: Some Further Results on Multinationals’ Locational Strategies.” Research Policy 31(4):589-609.

Berry, Heather. 2014. “Global Integration and Innovation: Multicountry Knowledge Generation within MNCs.” Strategic Management Journal 35:869-90.

Berry, Heather and Aseem Kaul. 2015. “Global Sourcing and Foreign Knowledge Seeking.” Management Science 61(5):1052-71.

Bessen, James and Robert M. Hunt. 2007. “An Empirical Look at Software Patents.” Journal of Economics and Management Strategy 16(1):157-89.

Bloom, Nicholas, Charles Jones, John Van Reenen, and Michael Webb. 2017. “Are Ideas Getting Harder to Find?” NBER Working Paper 23782.

Bound, John, Breno Braga, Joseph M. Golden, and Gaurav Khanna. 2015. "Recruitment of Foreigners in the Market for Computer Scientists in the United States." Journal of Labor Economics 33(S1):S187-223.

Branstetter, Lee, Matej Drev, and Namho Kwon. 2018. "Get With the Program: Software-Driven Innovation in Traditional Manufacturing.” Management Science.

Branstetter, Lee, Britta Glennon, and J.Bradford Jensen. 2018. KnowledgeTransfer Abroad: The Role of US Inventors within Global R\&D Networks.

Branstetter, Lee, Guangwei Li, and Francisco Veloso. 2015. “The Rise of International Co-Invention.” Pp. 135-68 in The Changing Frontier: Rethinking Science and Innovation Policy. Chicago, IL: University of Chicago Press.

Bresnahan, Timothy F. 1998. "The Changing Structure of Innovation in Computing: Sources and Threats to the Dominant US Position.”

Bresnahan, Timothy F. and M. Trajtenberg. 1995. “General Purpose Technologies 'Engines of Growth’?” Journal of Econometrics 65(1):83-108.

Brynjolfsson, Erik and Lorin Hitt. 1995. "ICT as a Factor of Production: The Role of Differences among Firms.” Economics of Innovation and Technology. 3:183-98.

Brynjolfsson, Erik and Kristina Mcelheran. 2015. Data in Action: Data-Driven Decision-Making in U.S. Manufacturing.

Chung, Wilbur and Juan Alcácer. 2002. "Knowledge Seeking and Location Choice of Foreign Direct Investment in the United States.” Management Science 48(12):1534-54. 
Chung, Wilbur and Stephen Yeaple. 2008. "International Knowledge Sourcing: Evidence from US Firms Expanding Abroad.” Strategic Management Journal 29:1207-24.

Edler, Jakob, Frieder Meyer-Krahmer, and Guido Reger. 2002. "Changes in the Strategic Management of Technology: Results of a Global Benchmarking Study.” R\&D ManagementD Management 32(2):149-64.

Florida, Richard. 1996. “The Globalization of R\&D: Results of a Survey of Foreign-Affiliated R\&D Laboratories in the USA.” Research Policy 26:85-103.

Foley, C.Fritz and William R. Kerr. 2013. "Ethnic Innovation and U.S. Multinational Firm Activity.” Management Science 59(7):1529-44.

Forman, Chris, Avi Goldfarb, and Shane Greenstein. 2016. “Agglomeration of Invention in the Bay Area: Not Just ICT.” American Economic Review: Papers \& Proceedings 106(5):146-51.

Freeman, Richard B. 2006. "People Flows in Globalization.” Journal of Economic Perspectives 20(2):145-70.

Furman, Jeffrey L., Michael E. Porter, and Scott Stern. 2002. "The Determinants of National Innovative Capacity.” Research Policy 31(2002):899-933.

Glennon, Britta. 2018. How Do Restrictions on High-Skilled Immigration Affect MNC Foreign Affiliate Activity?

Gordon, Robert J. 2016. The Rise and Fall of American Growth: The U.S. Standard of Living since the Civil War. Princeton University Press.

Graham, Stuart J. H. and David C. Mowery. 2003. "Intellectual Property Protection in the U.S. Software Industry.” Pp. 217-58 in Patents in the Knowledge-Based Economy, edited by W. M. Cohen and S. Merrill. Washington DC: National Academies Press.

Hall, Bronwyn H. 2010. "He Internationalization of R\&D.” 1-36.

Hall, Bronwyn H., Adam B. Jaffe, and Manuel Trajtenberg. 2001. "The NBER Patent Citations Data File: Lessons, Insights and Methodological Tools.” NBER Working Paper \#8498 (3094):1-74.

Hegde, Deepak and Diana Hicks. 2008. "The Maturation of Global Corporate R\&D: Evidence from the Activity of U.S. Foreign Subsidiaries.” Research Policy 37(3):390-406.

Helpman, Elhanan and Manuel Trajtenberg. 1998. "A Time to Sow and a Time to Reap: Growth Based on General Purpose Technologies.” Pp. 55-83 in General Purpose Technologies and Economic Growth, edited by E. Helpman. Cambridge, MA: MIT Press.

Hirschey, Robert C. and Richard E. Caves. 1981. "Research and Transfer of Technology By Multinational Enterprises.” Oxford Bulletin of Economics and Statistics 43(2):115-30.

Jones, Benjamin F. 2009. “The Burden of Knowledge and the 'Death of the Renaissance Man': Is Innovation Getting Harder?” Review of Economic Studies 76:283-317.

Kerr, Sari Pekkala and William R. Kerr. 2015. Global Collaborative Patents.

Kuemmerle, Walter. 1999. "The Drivers of Foreign Direct Investment into Research and Development: An Empirical Investigation.” Journal of International Business Studies 30(1):1.

Macher, Jeffrey T. and David C. Mowery. 2008. Innovation in Global Industries: U.S. Firms Competing in a New World: Collected Studies. edited by J. T. Macher and D. C. Mowery. Washington, D.C.: The National Academies Press.

Mansfield, By Edwin, David Teece, and Anthony Romeo. 1979. “Overseas Research and Development by US-Based Firms.” Economica 46(182):187-96.

Odagiri, Hiroyuki and Hideto Yasuda. 1996. "The Determinants of Overseas R\&D by Japanese Firms: An Empirical Study at the Industry and Company Levels.” Research Policy 25(7):1059-79.

Ronstadt, Robert C. 1977. "Research and Development Abroad by US Multinationals."

Serapio, Manuel G. and Donald H. Dalton. 1999. "Globalization of Industrial R\&D: An Examination of Foreign Direct Investments in R\&D in the United States.” Research Policy 28(2/3):303-16.

Shu, Pian and Claudia Steinwender. 2018. "Trade and Innovation.” Innovation Policy and the Economy. Siedschlag, Iulia, Donal Smith, Camelia Turcu, and Xiaoheng Zhang. 2013. "What Determines the Location Choice of R\&D Activities by Multinational Firms?” Research Policy 42(8):1420-30. Syverson, Chad. 2011. "What Determines Productivity?” Journal of Economic Literature 49(2):326-65. 
Thursby, Marie C. and Jerry G. Thursby. 2006. Here or There? A Survey of Factors in Multinational $R \& D$ Location. Washington, D.C.: The National Academies Press.

Zander, Ivo. 1999. "How Do You Mean `global’? An Empirical Investigation of Innovation Networks in the Multinational Corporation.” Research Policy 28(2-3):195-213.

von Zedtwitz, Maximilian and Oliver Gassmann. 2002. "Market versus Technology Drive in R\&amp;D Internationalization: Four Different Patterns of Managing Research and Development.” Research Policy 31(4):569-88.

Zhao, Minyuan. 2006. "Conducting R\&D in Countries with Weak Intellectual Property Rights Protection.” Management Science 52(8):1185-99. 
Table 1: Correlation between a multinational's software intensity, a country's software intensity, and the ensuing growth in foreign affiliate $R \& D$ expenditure

\begin{tabular}{|c|c|c|c|}
\hline & \multicolumn{3}{|c|}{$\begin{array}{l}\text { Dependent Variable: Growth in foreign affiliate R\&D expenditures } \\
\qquad \ln \left(R \& D_{i j 2014}\right)-\ln \left(R \& D_{i j s}\right)\end{array}$} \\
\hline & 1994-2014 & 1999-2014 & 2004-2014 \\
\hline \multirow[t]{2}{*}{ Highly software-Intensive $\mathrm{MNC}=1$} & $0.294 *$ & $0.290^{* *}$ & 0.0399 \\
\hline & $(0.173)$ & $(0.129)$ & $(0.121)$ \\
\hline \multirow[t]{2}{*}{ Country software Intensity } & $-0.0228 * * *$ & $-0.0152 * * *$ & $-0.00370 * *$ \\
\hline & $(0.00494)$ & $(0.0024)$ & $(0.00181)$ \\
\hline \multirow{2}{*}{$\begin{array}{l}\text { Highly software-Intensive MNC }=1 * \\
\text { Country software Intensity }\end{array}$} & 0.0117 & $0.0123^{* *}$ & $0.0104^{* *}$ \\
\hline & $(0.0107)$ & $(0.0058)$ & $(0.00504)$ \\
\hline Controls (in the base year) & \multicolumn{3}{|c|}{$\begin{array}{l}\text { The college-educated population, average compensation per worker, } \\
\text { GDP, GDP growth, parent R\&D expenditures, MNC global sales, mean } \\
\text { effective tax }\end{array}$} \\
\hline R-squared & 0.023 & 0.016 & 0.015 \\
\hline $\mathbf{N}$ & 18,846 & 24,250 & 26,096 \\
\hline
\end{tabular}

Notes: Each column represents a different long difference OLS regression. The dependent variable is the long difference of the natural log of foreign affiliate R\&D expenditure at the firm-country level between 2014 and a base year. Highly software intensive MNC is a dummy variable equal to one if the MNC belongs to the high software intensity group in the base year, and zero otherwise. High software intensity is measured using the $90^{\text {th }}$ percentile of MNC software citation-weighted patent stocks in that year. Country software intensity is measured using a moving cumulative stock of citation-weighted patents, where we use the yearly flow in 1980 to begin and then add yearly patent flow, depreciating the previous year's stock by $20 \%$ following Chung and Yeaple (2008). We then calculate the share of the software stock of all USPTO citation-weighted patents applied for in a given country in a given year, minus the relevant firm. To reduce volatility and noise in the shares variable, we restrict our sample to include only countries with at least a 500 patent stock. We multiply the shares by 100 for ease of interpretability. The set of controls include the number of over 25 year-olds that have completed a tertiary education ${ }^{25}, \ln$ (GDP in current USD), GDP growth ${ }^{26}$, the reporter's R\&D expenditures in the US in the base year, the total global sales of the multinational as a proxy for size in the base year, the mean effective tax rate in the country ${ }^{27}$, and the average compensation per worker ${ }^{28}$. Standard errors are clustered at the firm level. We make two other sample modifications for these regressions: (1) we remove the finance and insurance industry, since banks were only required to start reporting in the 200s, and (2) we removed countries that had fewer than 100 employees at all foreign affiliates across all firms. Firm-level cluster-robust standard errors appear in parentheses. ${ }^{* * *},{ }^{* *}$, and ${ }^{*}$ denote statistical significance at the 1,5 , and 10 percent levels, respectively.

${ }^{25}$ From the Barro-Lee human capital dataset.

${ }^{26} \mathrm{GDP}$ and GDP growth are both from the World Bank.

${ }^{27}$ Calculated using BEA data. We took all affiliates with positive net income that reported paying income tax, then computed the ratio of taxes paid to the sum of taxes paid and net income. Finally, we took the mean within each country/year, checking to make sure the rates are between 0 and 1 . These rates are not affiliate-specific but country/year-specific.

${ }^{28}$ Calculated using BEA data. We took all affiliates with positive R\&D expenditures, then divided compensation by number of employees for those foreign affiliates. We then took the mean within each country/year. These rates are not affiliate-specific but country/year-specific. 
Table 2: Correlation between a multinational's software intensity, a country's software intensity, and the ensuring growth in foreign affiliate $R \& D$ expenditure, on the extensive margin

\begin{tabular}{lllc}
\hline & \multicolumn{3}{c}{ Dependent Variable: Start of Foreign Affiliate R\&D } \\
& $\mathbf{1 9 9 4 - 2 0 1 4}$ & $\mathbf{1 9 9 9 - 2 0 1 4}$ & $\mathbf{2 0 0 4 - 2 0 1 4}$ \\
\hline Highly software-Intensive & $0.103^{* * *}$ & $0.0779^{* * *}$ & $0.0658^{* * *}$ \\
MNC=1 & $(0.0174)$ & $(0.0136)$ & $(0.0125)$ \\
Country software Intensity & $-0.00268^{* * *}$ & $-0.00162^{* * *}$ & $-0.000403^{*}$ \\
& $(0.000589)$ & $(0.000294)$ & $(0.000216)$ \\
Highly software-Intensive & $0.00305^{* * *}$ & $0.00140^{* *}$ & $0.00145^{* *}$ \\
MNC=1 * Country software & $(0.00118)$ & $(0.000657)$ & $(0.000565)$ \\
Intensity & The college-educated population, average compensation per worker, GDP, \\
Controls (in the base year) & GDP growth, parent R\&D expenditures, MNC global sales, mean effective \\
& tax & & \\
\hline R-squared & 0.023 & 0.030 & 0.031 \\
$\mathbf{N}$ & 18,846 & 23,508 & 25,071 \\
\hline
\end{tabular}

Notes: Each column represents a different long difference OLS (linear probability model) regression. The dependent variable is equal to one if the firm did not perform R\&D in that country in the base year, but they had begun doing so by 2014, and zero otherwise. Highly software intensive MNC is a dummy variable equal to one if the MNC belongs to the high software intensity group in the base year, and zero otherwise. High software intensity is measured using the $90^{\text {th }}$ percentile of MNC software citation-weighted patent stocks in that year. Country software intensity is measured using a moving cumulative stock of citation-weighted patents, where we use the yearly flow in 1980 to begin and then add yearly patent flow, depreciating the previous year's stock by $20 \%$ following Chung and Yeaple (2008). We then calculate the share of the software stock of all USPTO citation-weighted patents applied for in a given country in a given year, minus the relevant firm. To reduce volatility and noise in the shares variable, we restrict our sample to include only countries with at least a 500 patent stock. We multiply the shares by 100 for ease of interpretability. The set of controls include the number of over 25 year-olds that have completed a tertiary education ${ }^{29}, \ln \left(\right.$ GDP in current USD), GDP growth ${ }^{30}$, the reporter's R\&D expenditures in the US in the base year, the total global sales of the multinational as a proxy for size in the base year, the mean effective tax rate in the country $^{31}$, and the average compensation per worker ${ }^{32}$. Standard errors are clustered at the firm level. We make two other sample modifications for these regressions: (1) we remove the finance and insurance industry, since banks were only required to start reporting in the 200s, and (2) we removed countries that had fewer than 100 employees at all foreign affiliates across all firms. Firm-level cluster-robust standard errors appear in parentheses. ***, **, and * denote statistical significance at the 1,5 , and 10 percent levels, respectively.

\footnotetext{
${ }^{29}$ From the Barro-Lee human capital dataset.

${ }^{30} \mathrm{GDP}$ and GDP growth are both from the World Bank.

${ }^{31}$ Calculated using BEA data. We took all affiliates with positive net income that reported paying income tax, then computed the ratio of taxes paid to the sum of taxes paid and net income. Finally, we took the mean within each country/year, checking to make sure the rates are between 0 and 1 . These rates are not affiliate-specific but country/year-specific.

${ }^{32}$ Calculated using BEA data. We took all affiliates with positive R\&D expenditures, then divided compensation by number of employees for those foreign affiliates. We then took the mean within each country/year. These rates are not affiliate-specific but country/year-specific.
} 


\section{Figure 1}

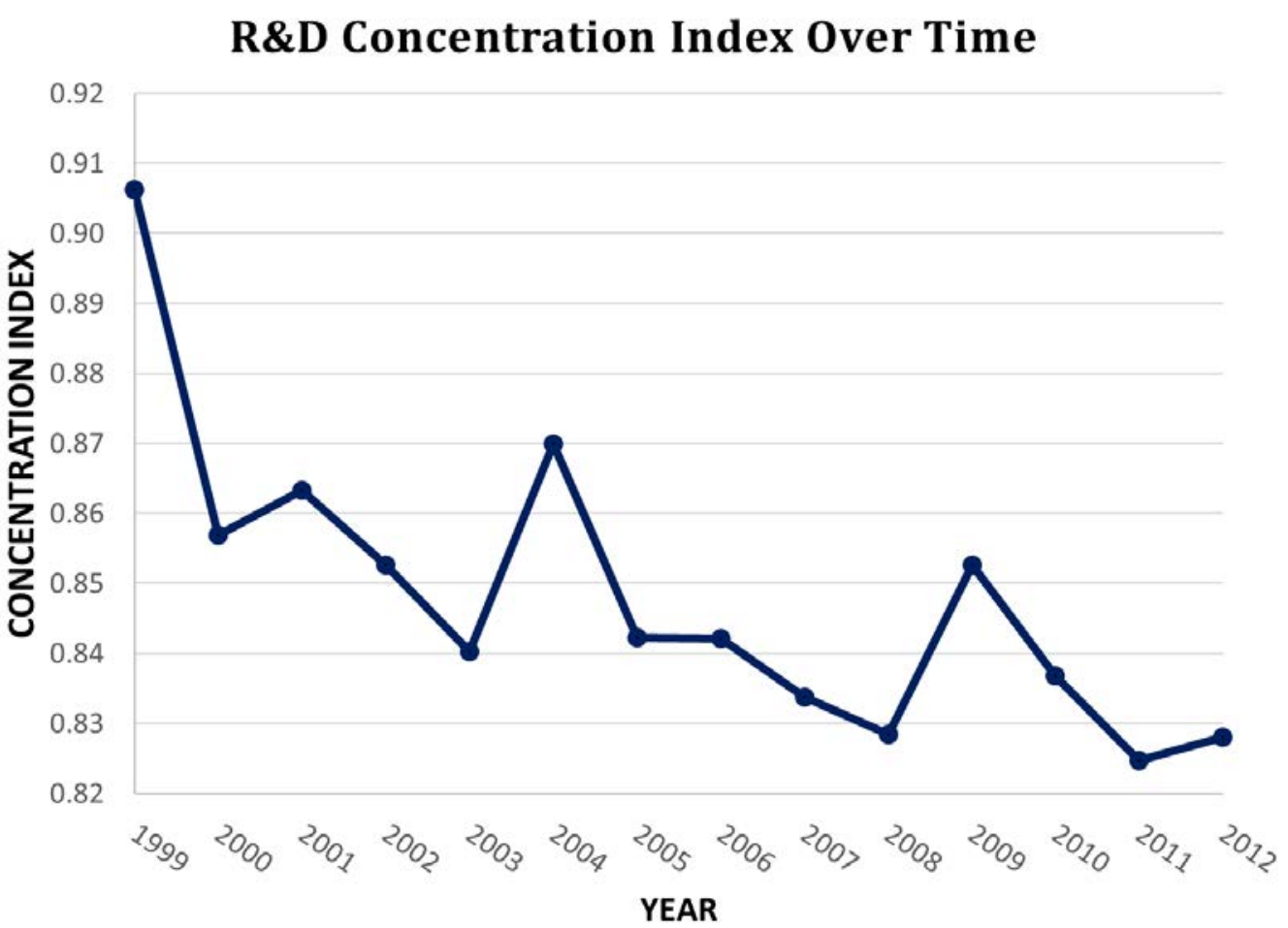

The above figure shows that R\&D is becoming less concentrated geographically; US multinationals are doing R\&D in more and more countries over time. We calculated one index for each MNC in each year as follows, and this graph shows the average index across all MNCs:

$$
H=\sum_{i=1}^{N} s_{i}^{2}
$$

Where $\mathrm{s}$ is share of total R\&D expenditures being done in country $\mathrm{i}$ by a given firm, and $\mathrm{N}$ is the number of countries (including the US). $\mathrm{H}=1$ indicates that a firm is only doing R\&D in one country (probably the US). 
Figure 2

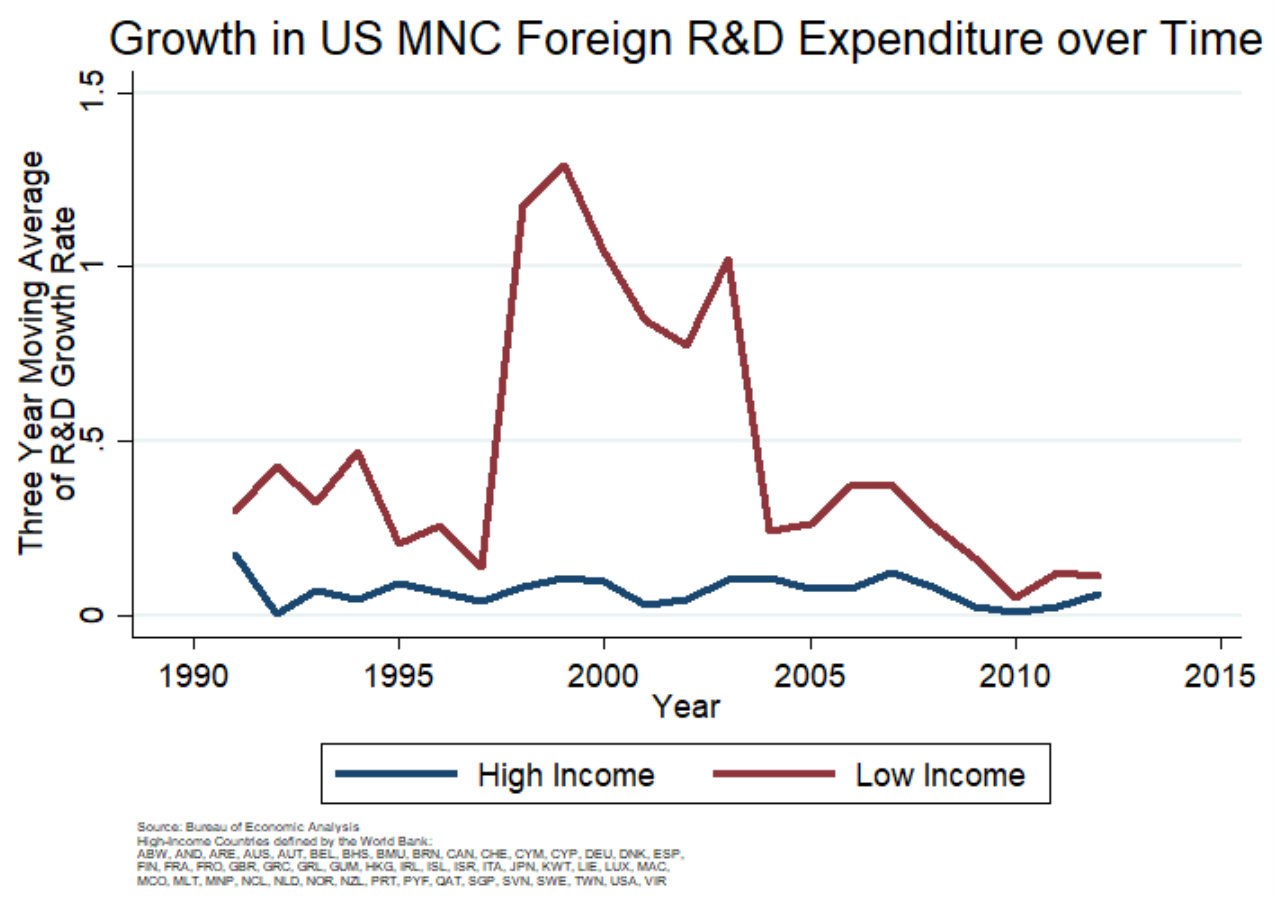




\section{Figure 3}

R\&D PERFORMED, BY INDUSTRY OF AFFILIATE IN 2014

"OLD HUBS"

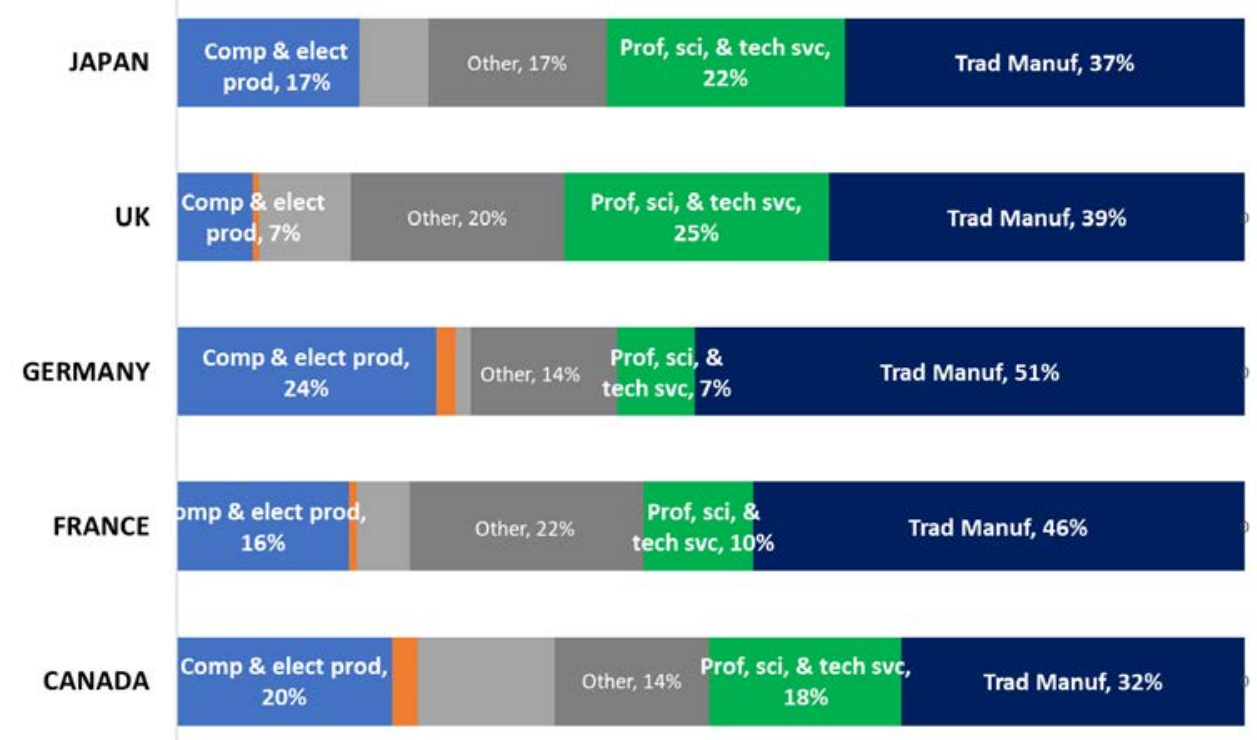

R\&D PERFORMED, BY INDUSTRY OF AFFILIATE IN 2014 "NEW HUBS"

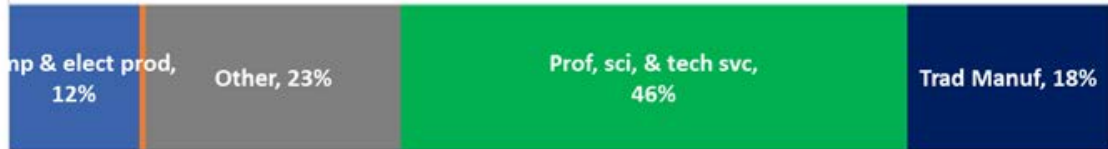

CHINA

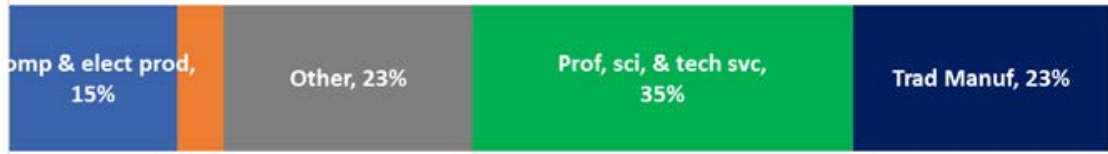

ISRAEL

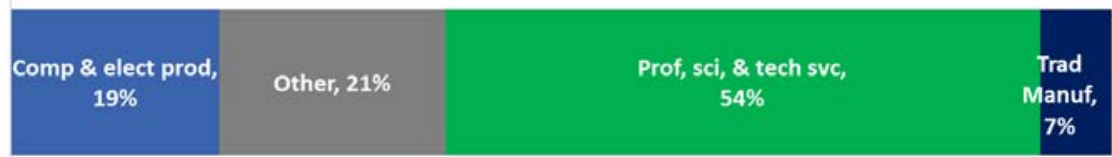

Notes: "Trad Manuf” refers to Chemical, Food, Machinery, Primary \& Fabricated Metals, Transportation Equipment. Other includes mining, trade, and other. "Prof, Sci, \& tech svc" is Professional, scientific, and technical services. "Comp \& elect prod" is computer and electronics products manufacturing. The orange shade is for electrical equipment, appliances, and components manufacturing. The light grey is for information. The graphs illustrate that the specialization of "new hubs" like India, China, and Israel look very different from the specialization of "old hubs" like Japan, the UK, Canada, France, and Germany. Source is BEA public data. 
Figure 4

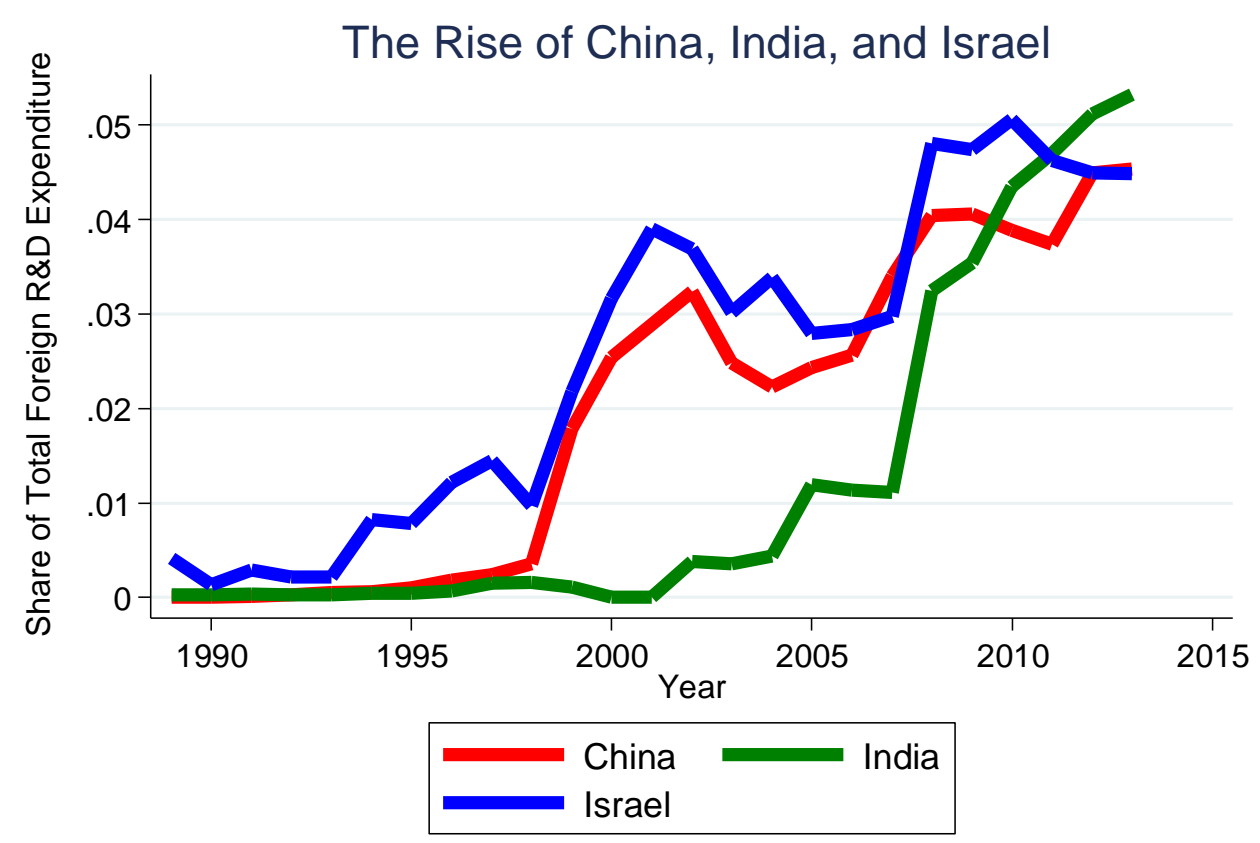

Source: Bureau of Economic Analysis

Figure 5

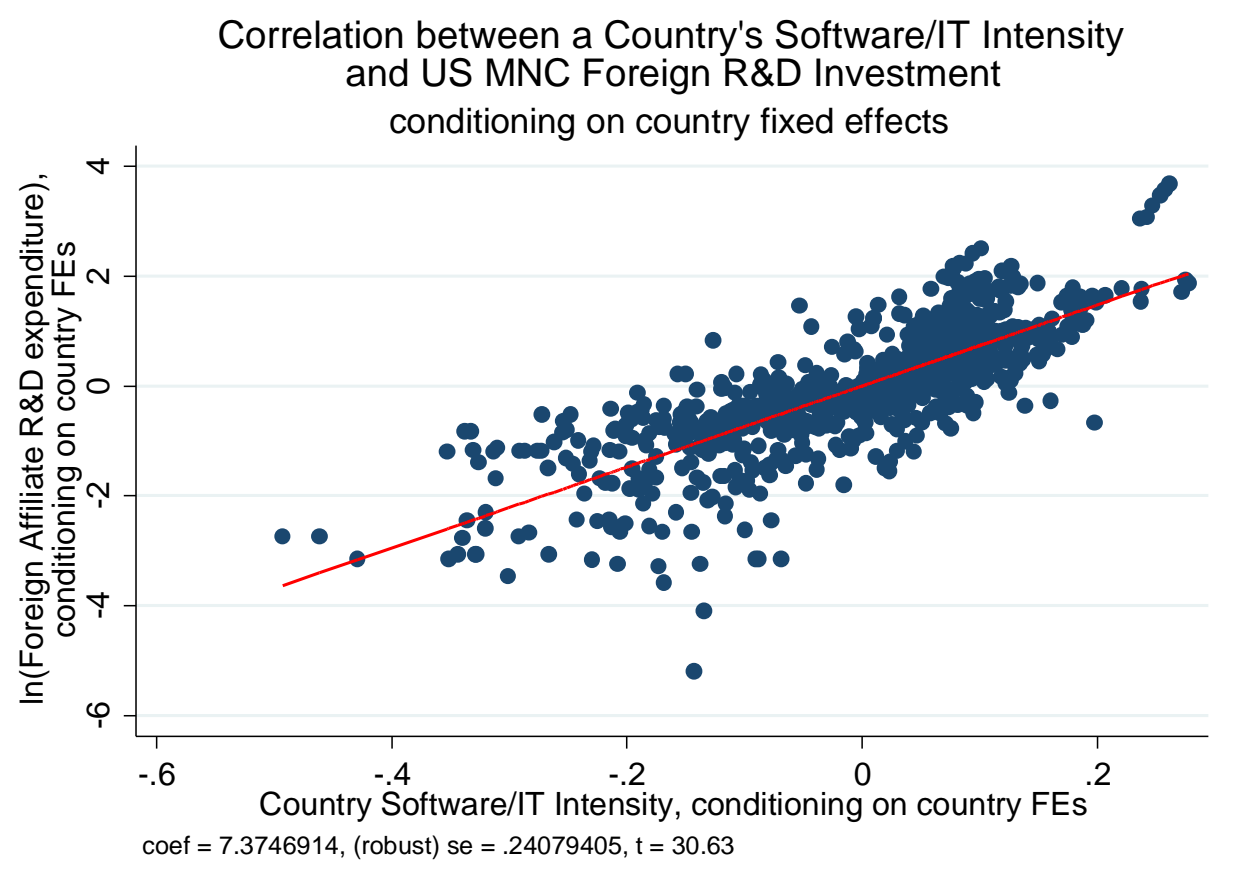

Source: BEA and USPTO. Each point represents a country-year observation. 
Figure 6

Correlation between a Firm's Software \& IT hardware Stock and

the $\%$ of Patents with a Non-High Income Foreign Inventor in 2012

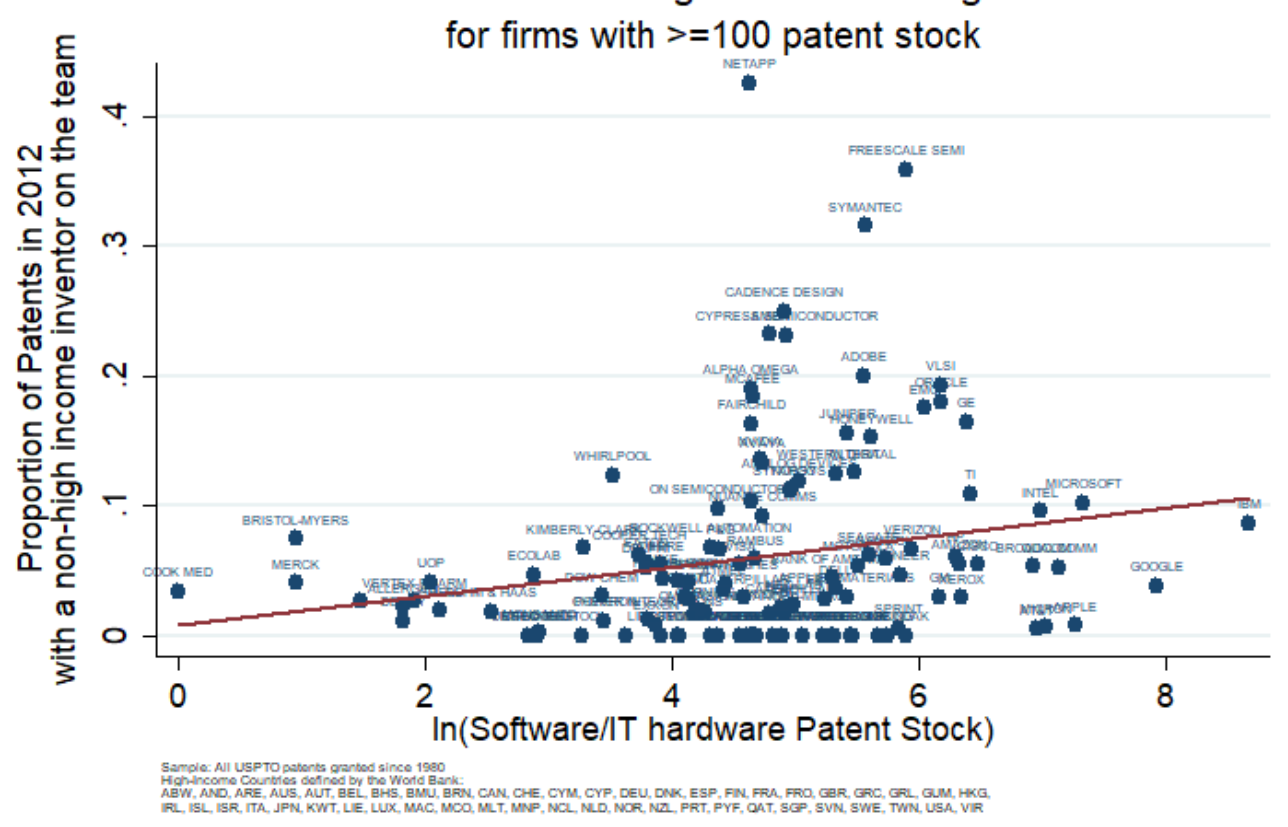

Note: the selection of firms in this scatterplot do not come from the Bureau of Economic Analysis data; they come from USPTO patent data.

\section{Figure 7}

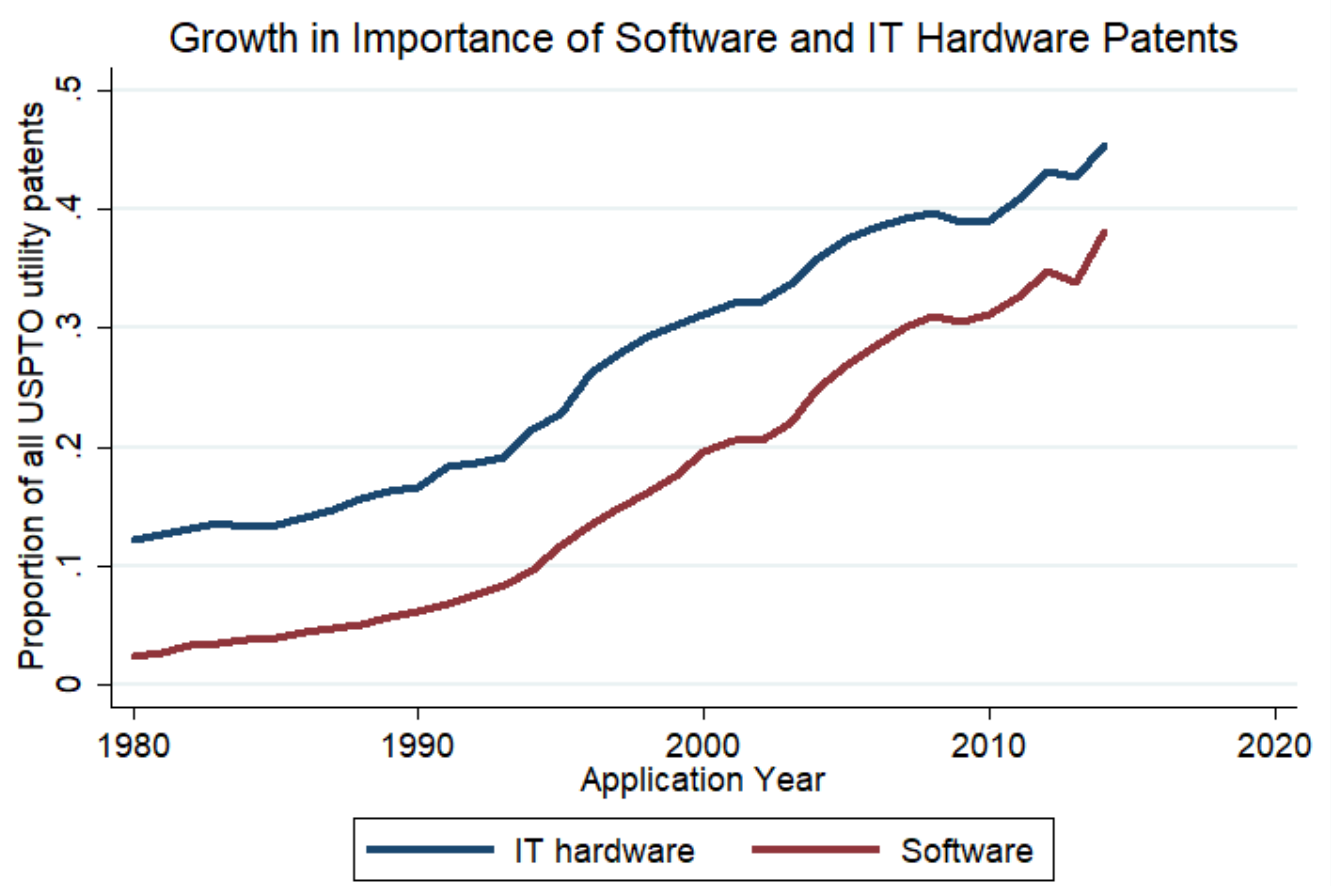

Source: USPTO 
Figure 8
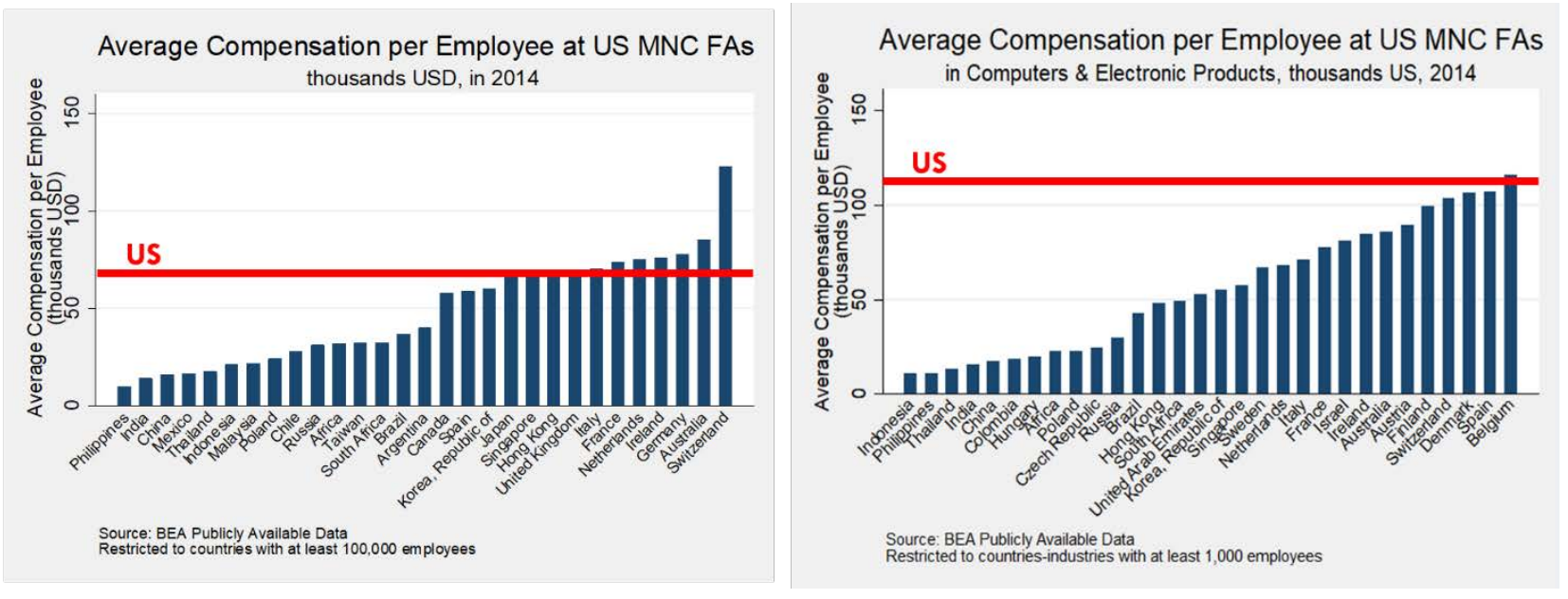

Figure 9

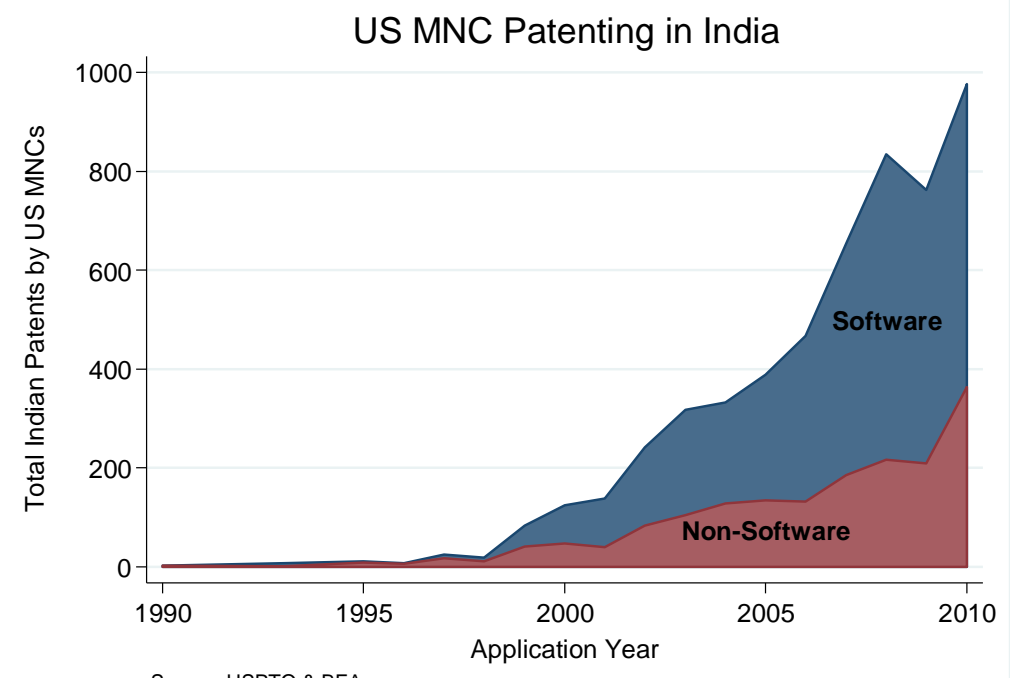

Source: USPTO \& BEA

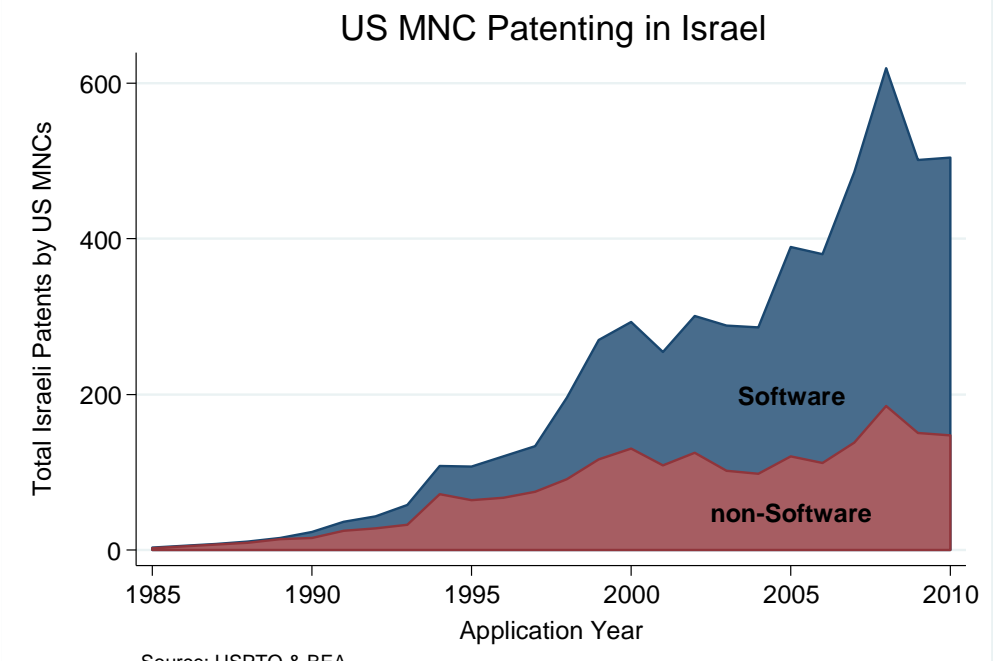

Source: USPTO \& BEA 